\title{
POLARIZATION OF DENTAL CARIES AMONG INDIVIDUALS AGED 15 TO 18 YEARS
}

\author{
Fernando Neves HUGO ${ }^{1}$, Glauber Campos VALE ${ }^{1}$, Renzo Alberto CCAHUANA-VÁSQUEZ ${ }^{1}$, \\ Silvia CYPRIANO², Maria da Luz Rosário de SOUSA ${ }^{3}$
}

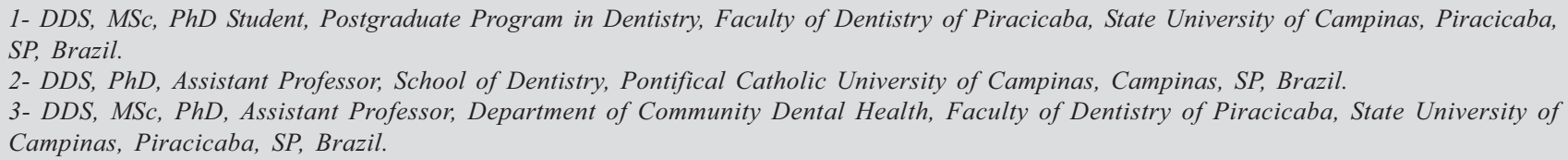

Corresponding Address: Fernando Neves Hugo - Laboratório de Bioquímica, Avenida Limeira 901, Bairro Areião, CP-52 - 13414-903, Piracicaba, SP, Brasil - Phone: 5519 2106-5393 - e-mail: fnhugo@yahoo.com.br

Received: April 07, 2006 - Modification: September 15, 2006 - Accepted: May 22, 2007

\begin{abstract}
$O$

bjective: To evaluate the role of socioeconomic variables and self-perceived oral health in the polarization of caries among adolescents in Santa Bárbara D’Oeste, Brazil. Material and Methods: Cross-sectional study. Sampling was randomized and sample size was defined according to WHO criteria. Two hundred and seventy seven adolescents (15 to 18 year-old) were examined by five trained examiners that assessed DMFT index according to WHO criteria. Self-perceived oral health, access to dental services and socio-demographic variables were self-reported. Student's t tests, chi-square tests, and multivariate logistic regression (with significant caries index $(\mathrm{SiC})$ as the outcome), were performed. Results: Mean DMFT was 5.48 ( \pm 4.22 ) and the proportion of "caries free" subjects was $15.5 \%$. Mean DMFT (9.71 \pm 2.85$)$ and mean D (1.67 \pm 2.18$)$ of SiC positive subjects were significantly higher than mean DMFT $(2.88 \pm 2.17)$ and mean D $(0.45 \pm 0.87)$ of SiC negative subjects $(\mathrm{p}<0.0001)$. Mean D of white $(0.76 \pm 1.51)$ was significantly smaller than mean D of non-white subjects $(1.32 \pm 2.01)$. The only variable independently associated with the "SiC positive" outcome was "report of toothache within six months prior to the study" [OR=1.83 (95\%CI 1.08 to 3.12)], $\mathrm{p}<0.001$. Conclusion: $\mathrm{SiC}$ was associated with "report of toothache" but not with sociodemographic variables in the studied population.
\end{abstract}

Uniterms: Adolescent; Dental caries; Epidemiology.

\section{INTRODUCTION}

Children has been the target of oral health promotion policies for a long time in Brazil, and this is due to several prevalence studies that were carried out during the 1980's and 1990's, showing that children are the part of population most susceptible to dental caries and also the most benefited from prevention programs. There are, however, few population-based studies evaluating the prevalence and progression of dental caries among adolescents and young adults in Brazil $^{10}$. This is the phase in which the population is no longer a target for epidemiological surveys and preventive programs in oral health ${ }^{27}$.

Although a decrease in the prevalence of dental caries was observed in several countries, there was also a skewed distribution of dental caries in the 12-year-old age range. In fact, part of the 12-year-old individuals has high or very high DMFT values while the rest has low DMFT values or is "caries free"19. Thus, to identify this part of population with high or very high DMFT values and to target the still caries-susceptible individuals, a new index, named significant caries index ( $\mathrm{SiC}$ ), was proposed by Bratthall ${ }^{4}$ (2000) to bring attention to the children with the highest caries scores in a given population. It is represented by the mean DMFT of the one-third of the individuals having the highest of DMFT values in a specific population ${ }^{19}$.

According to Baldani, et al. ${ }^{2}$ (2004), the polarization of dental caries is a phenomenon associated with economic deprivation. Socioeconomic factors have also been identified as risk indicators to the development of dental caries ${ }^{24}$. In addition, $\mathrm{SiC}$ is considered a good indicator to compare the risk of dental caries between different groups ${ }^{17}$. Therefore, $\mathrm{SiC}$ was chosen in the present study to evaluate which variables were associated with high and very high DMFT values in adolescents from the city of Santa Bárbara D’Oeste, Brazil.

An evaluation of variables related to self-perceived oral health was made because recent evidence have shown that self-perceived need for dental care is strongly associated with fractured fillings, cavities, tooth mobility, among 
others $^{12}$.

Thus, the purpose of this study was to estimate the prevalence of dental caries, to calculate $\mathrm{SiC}$ and to evaluate the role of socioeconomic variables and self-perceived oral health measures in the polarization of dental caries in adolescents aged 15-18 years living in Santa Bárbara D’Oeste, SP, Brazil.

\section{MATERIALAND METHODS}

The city of Santa Barbara D'Oeste has 20 schools, of which 16 are public and the remaining 4 are private. The city had 17,062 inhabitants aged 15 to 19 years in 2002. In 2004, 8,185 subjects aged 15 to 18 years were attending the public $(\mathrm{n}=7,867)$ and private $(\mathrm{n}=318)$ high schools of Santa Barbara D'Oeste. Adolescents from twelve of the sixteen public schools were randomly selected using a table of random numbers generated with software Microsoft Excel and the list of students provided by the Department of Education of Santa Barbara D'Oeste. The twelve schools were selected to represent three out of the four distinct districts of Santa Barbara D'Oeste. The number of adolescents examined at each school was proportional to the population of adolescents studying at each public School in the city. Data collection was performed during 2002.

\section{Study Design}

This cross-sectional study, approved by the Ethics in Research Committee of the Faculty of Dentistry of Piracicaba (Research Protocol \#089/2002) was carried out in accordance with the resolution 196/96 of the Brazilian Health Council, which regulates ethical issues related to human studies.

A sample size of 345 subjects was calculated using the criteria used in the SP 98 survey, according to the methodology proposed by the World Health Organization (WHO). The adolescents aged 15 to 18 years were invited to take part in the study and, upon acceptance, informed written informed consents were granted by the subjects themselves or their parents/representatives if under 18 years of age . $^{30}$.

Santa Bárbara D'Oeste is located in the metropolitan area of Campinas and $130 \mathrm{~km}$ away from the city of São Paulo. In the year 2000, the city had 169,574 inhabitants and $100 \%$ of its households with electricity and fluoridated water supply, according to the Brazilian census.

\section{Instruments}

Teeth were evaluated using DMFT index, in accordance with the criteria proposed by the World Health Organization ${ }^{30}$ (1997). Five examiners using flat dental mirrors and CPI probes ("ball point") performed the dental examinations under natural light conditions. All examiners were previously trained in a 32-hour program by experienced professionals from the Health Department of Santa Bárbara D'Oeste and from the Social Dentistry Department of the Faculty of Dentistry of Piracicaba.

Self-perceived oral health, access to dental services and socio-demographic variables were assessed with an adapted version of the structured inventory proposed by the Brazilian Ministry of Health during the National Oral Health Survey ${ }^{5}$ in 2004. Race was assessed by the examiners and participants were regarded as white, mixed, native Brazilian, yellow or black and later categorized into whites or non-whites for analytical purposes. Housing status was self-reported with participants answering if their households were owned, rented or yielded by their relatives/legal representatives. Later, housing status was categorized into own or rent/yield for analytical purposes. Subjects were also asked about the number of rooms in their homes, a continuous variable that was later categorized into equal or bellow to the lower tertile $(=$ or $<4)$ or above the lower tertile $(=$ or $>4)$ of distribution of the studied sample. Family income was self-reported and a monthly family income equal or bellow to the first tertile (i.e., R\$ 1,000.00) of the distribution was considered an indicator of financial disadvantage in the studied sample. Participants were asked if their relatives or representative had a car. The possible answers for this question were "yes" or "no". The following questions were used to assess selfperceived oral health: 1. "How would you classify the health of your teeth and gingiva?", and 2. "How would you classify the appearance of your teeth and gingiva?" Answers were in a Likert-type scale and ranged for both questions from extremely poor to extremely good and were later categorized into good and not good. The occurrence of toothache within the six months prior to the study was also self-reported, with subjects answering yes or no to this question.

\section{Statistical Analysis}

DMFT index means, Mean number of decayed teeth and the proportion of "caries free" subjects were described according to age, gender and race evaluated in this study. Chi-square tests were used for dichotomic variables while Student's t-tests were used for continuous. The correspondent non-parametric tests were used when appropriate. The value to reject the null hypothesis was set at $\mathrm{p}=0.05$.

The intra and inter-examiner reliability of the before study obtained data were summarized by Kappa coefficient and percentage of agreement. Associations were adjusted for the demographic and socioeconomic confounders, as well as for self-perceived oral health and access to dental services by means of the multivariate logistic regression. SiC was set as the outcome and those subjects with high or very high DMFT values (i.e., those in the group of subjects of the higher third of caries experience in the sample) were regarded as "SiC positive" while those with low DMFT or without caries were regarded as "SiC negative".

All statistical analyses were carried out using the SPSS 11.0 software (SPSS Inc., Chicago, IL, USA). All independent variables that showed association with $p<0.25$, as well as those with clinical-epidemiological relevance, according to data in the literature, were candidates to the multivariate model ${ }^{14}$. Variables that did not contribute (i.e., $\mathrm{p}>0.25$ ) to the model were eliminated and a new model was calculated. The new model was always compared to the previous one using 
the likelihood ratio test. Adjusted odds ratios (OR) are shown with the $95 \%$ confidence intervals (95\% CI).

\section{RESULTS}

Two hundred and seventy seven adolescents aged 15 to 18 years were evaluated. The response rate was $80.3 \%$ and non-response was related to inability to provide relatives' consent to participate or being absent of class in the day of clinical examinations. Before study intraexaminer reproducibility of the DMFT was 0.96 or higher while before study inter-examiner reproducibility ranged from 0.70 to 0.84 .

Mean DMFT, mean number of decayed teeth and the proportion of "caries free" subjects regarding the different ages, genders and race evaluated in this study are shown in Table 1. The mean DMFT of the studied sample was 5.48 $( \pm 4.22)$, while the mean number of decayed teeth was 0.91 $( \pm 1.67)$ and the proportion of "caries free" subjects was $15.5 \%$. No statistically significant differences were observed for mean DMFT, mean number of decayed teeth and proportion of "caries free" subjects between males and females. Mean DMFT and proportion of "caries free" subjects was also not significantly different between "whites" and "non-whites". However, there was a significant difference regarding the mean number of decayed teeth between "whites" $[0.76( \pm 1.51)]$ and "non-whites" [1.32 $( \pm 2.01)], \mathrm{p}=0.016$.

The characteristics of the sample, regarding the SiC outcome, are shown in Table 2. There was a significantly higher number of subjects that reported toothache in the six months prior to the study among the SiC positive subjects (47.8\% versus $33.3 \%), p<0.0001$. Mean DMFT $(9.71 \pm 2.85)$ and mean number of decayed teeth $(1.67 \pm 2.18)$ of the $\mathrm{SiC}$ positive subjects were significantly higher than the mean
DMFT (2.88 \pm 2.17$)$ and the mean number of decayed teeth $(0.45 \pm 0.87)$ of the $\mathrm{SiC}$ negative subjects, $\mathrm{p}<0.0001$.

The only variable associated independently with the $\mathrm{SiC}$ positive outcome was the toothache reported within the six months prior to the study [OR=1.83 (95\% CI: 1.08 to 3.12$)$ ], (Table 3).

\section{DISCUSSION}

Although dental caries has been the most commonly investigated oral disease, most studies focus on children, and studies on caries among adolescents and young adults are scarce ${ }^{27}$. The lack of basic epidemiological information about dental caries among adolescents constitutes a serious limitation due to two main reasons. Firstly, to keep an adequate surveillance of dental caries it is important to know its behavior in all age groups. Secondly, with the decline of dental caries in several countries, including Brazil, the chances of extending oral health care to other groups of the population, such as adolescents and young adults, increased significantly ${ }^{10}$.

The first National Brazilian study with 15-19 year-olds was performed in 1986 and reported a mean DMFT of 12.70 for Brazil, and 12.40 for the southeast region, which includes Santa Bárbara D'Oeste ${ }^{20}$. When the mean value of DMFT in 1986 is compared with the mean DMFT for the $15-18$ yearolds of Santa Bárbara D'Oeste in 2002, a clear decrease in the prevalence of dental caries is observed, confirming a tendency observed in several industrialized countries. When the values for the 15-19 year-olds from the state of São Paulo in 2002 are evaluated (Mean DMFT $=6.44)^{5}$, the same tendency of a decline in the caries prevalence is observed.

When the variable race was categorized as "whites" and "non-whites", a significant association between "non-

TABLE 1- Means ( \pm standard-deviations) of DMFT index, number of decayed teeth and proportion of "caries free" subjects regarding the different ages, genders and races evaluated in Santa Bárbara D'Oeste, SP, Brazil

\begin{tabular}{|c|c|c|c|}
\hline & $\mathrm{DMFT}(\mathrm{m} \pm \mathrm{sd})$ & Decayed $(m \pm s d)$ & Caries Free \\
\hline \multicolumn{4}{|l|}{ Age (in years) } \\
\hline 15 & $4.20( \pm 3.48)$ & $1.16( \pm 1.92)$ & $20.0 \%$ \\
\hline 16 & $5.03( \pm 4.36)$ & $1.03( \pm 1.94)$ & $19.2 \%$ \\
\hline 17 & $5.63( \pm 3.79)$ & $0.61( \pm 0.95)$ & $13.4 \%$ \\
\hline 18 & $7.10( \pm 4.32)$ & $0.66( \pm 1.06)$ & $8.0 \%$ \\
\hline Total (15 to 18$)$ & $5.48( \pm 4.22)$ & $0.91( \pm 1.67)$ & $15.5 \%$ \\
\hline \multicolumn{4}{|l|}{ Gender } \\
\hline Male & $5.75( \pm 4.23) \mathrm{a}$ & $0.89( \pm 1.60) a$ & $14.0 \% \mathrm{a}$ \\
\hline Female & $5.05( \pm 4.07) \mathrm{a}$ & $0.93( \pm 1.78) \mathrm{a}$ & $17.9 \% a$ \\
\hline \multicolumn{4}{|l|}{ Race } \\
\hline White & $5.32( \pm 4.09) a$ & $0.76( \pm 1.51) a$ & $14.0 \% a$ \\
\hline Non-white & $5.93( \pm 4.56) a$ & $1.32( \pm 2.01) b$ & $17.9 \% a$ \\
\hline
\end{tabular}

Different letters represent statistic significant difference. Mann-Whitney test, $p=0.016$ 
whites" and the mean number of decayed teeth was observed (Mann-Whitney test, $\mathrm{p}=0.016$ ). These results are in accord with the results from a study performed by our group in preschool children of Piracicaba ${ }^{6}$, a city located close to Santa
Bárbara D'Oeste where the mean number of decayed teeth among "non-whites" 5-6 year-olds was observed to be significantly higher than the mean number of decayed teeth among "whites". These findings indicate that further studies

TABLE 2- Characteristics of the population studied in Santa Bárbara D'Oeste, SP, Brazil, in respect to the outcome

\begin{tabular}{|c|c|c|c|}
\hline Characteristics & SiC negative subjects $(\mathrm{N}=174)$ & SiC positive subjects $(\mathrm{N}=103)$ & $\mathbf{P}$ \\
\hline \multicolumn{4}{|l|}{ Age (\%) } \\
\hline 15 & $30.2 \%$ & $19.8 \%$ & $0.14^{\mathrm{a}}$ \\
\hline 16 & $29.6 \%$ & $29.2 \%$ & \\
\hline 17 & $24.9 \%$ & $26.0 \%$ & \\
\hline 18 & $15.4 \%$ & $25.0 \%$ & \\
\hline \multicolumn{4}{|l|}{ Gender (\%) } \\
\hline Female & $59.2 \%$ & $66.7 \%$ & $0.24^{\mathrm{a}}$ \\
\hline \multicolumn{4}{|l|}{ Race } \\
\hline White & $73.6 \%$ & $68.8 \%$ & \\
\hline Non-white & $23.7 \%$ & $31.3 \%$ & $0.20^{\mathrm{a}}$ \\
\hline \multicolumn{4}{|l|}{ Housing Status } \\
\hline Own & $78.0 \%$ & $79.8 \%$ & $0.87^{a}$ \\
\hline Rent/yielded & $22.0 \%$ & $20.2 \%$ & \\
\hline \multicolumn{4}{|l|}{ Number of rooms } \\
\hline$=$ or $<4$ & $33.3 \%$ & $25.6 \%$ & $0.25^{\mathrm{a}}$ \\
\hline$>4$ & $66.7 \%$ & $74.4 \%$ & \\
\hline \multicolumn{4}{|l|}{ Family income } \\
\hline$<\mathrm{R} \$ 1000.00$ & $76.8 \%$ & $70.1 \%$ & $0.32^{\mathrm{a}}$ \\
\hline$=$ or $>\mathrm{R} \$ 1000.00$ & $23.2 \%$ & $29.9 \%$ & \\
\hline \multicolumn{4}{|l|}{ Car } \\
\hline Yes & $62.9 \%$ & $58.9 \%$ & $0.59^{a}$ \\
\hline \multicolumn{4}{|l|}{ Self-perceived oral health } \\
\hline Good & $94.6 \%$ & $94.2 \%$ & $1.0^{\mathrm{a}}$ \\
\hline \multicolumn{4}{|l|}{$\begin{array}{l}\text { Appearance of teeth } \\
\text { and gingiva }\end{array}$} \\
\hline Good & $93.4 \%$ & $90.7 \%$ & $0.45^{a}$ \\
\hline \multicolumn{4}{|l|}{$\begin{array}{l}\text { Toothache in the six months } \\
\text { prior to the study }\end{array}$} \\
\hline Yes & $33.3 \%$ & $47.8 \%$ & $0.03^{a}$ \\
\hline DMFT (mısd) & $2.88 \pm 2.17$ & 9.712 .85 & $0.000^{b}$ \\
\hline 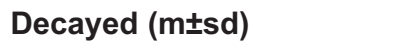 & $0.45 \pm 0.87$ & 1.672 .18 & $0.000^{\mathrm{b}}$ \\
\hline Family income in $R \$(m \pm s d)$ & $924,94 \pm 478,64$ & $1.076,30 \pm 668.55$ & $0.08^{b}$ \\
\hline Years of education & $9.87 \pm 1.37$ & 10.301 .35 & $0.33^{c}$ \\
\hline
\end{tabular}

${ }^{\mathrm{a} C h i-s q u a r e}$ test. ${ }^{\mathrm{b}}$ Mann-Whitney test. 'Student's t-test.

TABLE 3- Adjusted odds ratios (OR) and 95\% Confidence Intervals of the variable "toothache in the six months prior to the study" in relation to the outcome SiC in Santa Bárbara D'Oeste, SP, Brazil

Variable

SiC negative (reference)

SiC positive
Toothache in the six months prior to the study

1.0

1.83 (1.08 to 3.12$)$

-2 Log Likelihood $=344.43$. 
are needed to evaluate the association between untreated caries experience and deprived populations in Brazil, as well as the variables influencing this complex relationship.

Similarly to our study, a survey with North American adults ${ }^{21}$ showed a disproportional distribution of caries in different races. The findings of this study showed that AfroAmericans were more likely to have untreated dental caries than Non-Hispanic whites, even after controlling material factors, such as poverty, education and employment, and behavioral factors, such as marital status, tobacco use, alcohol use and obesity ${ }^{21}$.

Multivariate logistic regression was performed with $\mathrm{SiC}$ index as the outcome. The findings of our study indicate that the only variable associated with $\mathrm{SiC}$ was "toothache reported in the six months prior to the study". In addition, socio-demographic variables were unable to explain the outcome (i.e., were not significantly associated with $\mathrm{SiC}$ ), contradicting, in this age group, the previous evidence that demonstrated an association between $\mathrm{SiC}$ and socioeconomic status in a Brazilian population of 11 to 12 year-old childen, ${ }^{1}$. Further studies are needed to elucidate which variables are associated with inequalities in caries distribution in Brazilian adolescents.

The association between "toothache reported in the six months prior to the study" and $\mathrm{SiC}$ among the 15 to 18 yearolds of Santa Bárbara D'Oeste may be due to the difficulties in accessing dental services because in this age range students are no longer target of oral health care and prevention programs carried out in the schools ${ }^{27}$. There is some research-based evidence supporting this hypothesis. In a study performed with 11 to 12 year-olds in the state of São Paulo, Brazil, SiC was significantly associated with the access to dental services ${ }^{1}$. However, another feasible explanation to our results lies on the fact that dental pain itself is a result of progressive and untreated dental caries, which was also significantly more prevalent among $\mathrm{SiC}$ positive adolescents in our study. This hypothesis is supported by the findings from a study performed in a sample of young male adults in Brazil where previous history of dental pain was a risk indicator of untreated dental caries ${ }^{3}$. Thus, the results must be interpreted with caution, since dental pain is not a cause for caries, but caused by its progression into dentine and pulp.

Although socioeconomic factors played a significant role in the reduction of dental caries observed in the last decades ${ }^{18}$ and that several evidences indicate that caries is polarized among underprivileged groups $s^{9,11,13,28}$, our findings do not support the association between socioeconomic variables and caries polarization, as represented by $\mathrm{SiC}$, in the population of 15 to 18 year-olds evaluated in the city of Santa Bárbara D'Oeste. This might be due to difficulties in accessing dental health services, as discussed above, or a result of methodological weakness of our study, since we evaluated only students from public schools, known to represent a homogenous group of adolescents in Brazil. The lack of students from private schools represented an important limitation of our study because generalization of results is affected by the fact that only students from public schools were evaluated. Students from private schools were not included because there were few subjects attending such schools and also because they did not represent the users of the public dental health services in the city, and the data gathered from study were intended to be used in the planning of public health policies and actions by the Department of Heath of Santa Barbara D'Oeste. An analysis to assess if non-participants differed significantly from participants in terms of socio-demographic variables was not carried out and the effects of non-participants should be taken into account when interpreting the results from this study.

There are several findings in the literature, including evidences from Brazilian studies ${ }^{8,23,25}$, indicating that selfperceived oral health, dental health behavior, and motivation to dental hygiene among adolescents are influenced by the societies to which they belong ${ }^{15,16,26}$. Although significant differences were observed regarding caries levels when adolescents were grouped by their $\mathrm{SiC}$ status, most subjects from both groups rated their oral health as good (Table 2). These findings are in accordance with the literature that shows low predictive values and sensibility of self-rated oral health measures, when compared with dental treatment needs of adults ${ }^{22}$ and normative evaluations (e.g. complete clinical exams) of young adults ${ }^{29}$.

Pain is usually described as an unpleasant sensation. Its condition of symptom also makes the possibility of a disease implicit. The fact that the words pain and disease have a common etymologic origin in Portuguese (in Latin pain is dolor and disease is dolentia) is, by itself, representative of the intimate relation that exists between pain experience and the recognition of a disease by a subject ${ }^{7}$ and may help explaining the significant association between the variable "reporting toothache in the six months prior to the study" and SiC observed in the present study.

\section{CONCLUSIONS}

The findings of this study showed, concerning the population of adolescents from Santa Bárbara D'Oeste, that the $\mathrm{SiC}$ was significantly associated with the "report of toothache in the six months prior to the study", even after controlling of confounders. In conclusion, further studies are needed to elucidate the other factors associated with inequalities in the distribution of dental caries among adolescents, including adolescents from private schools in order to allow generalization of results based on large and representative samples of adolescents and focusing on the role of the access to dental health services because this is the age range in which students are no longer a target of oral health care and prevention programs. 


\section{REFERENCES}

1- Antunes JL, Narvai PC, Nugent ZJ. Measuring inequalities in the distribution of dental caries. Community Dent Oral Epidemiol. 2004;32:41-8

2- Baldani MH, Vasconcelos AGG, Antunes JLF. Association of the DMFT index with socioeconomic and dental services indicators in the state of Paraná, Brazil. Cad Saude Publica. 2004;20:143-52.

3- Bastos JL, Nomura LH, Peres MA. Dental pain, socioeconomic status, and dental caries prevalence in young male adults from southern Brazil. Cad Saude Publica. 2005;21(5):1416-23.

4- Bratthall D. Introducing the significant caries index together with a proposal for a new global oral health goal for 12 -year-olds. Int Dent J. 2000;50:378-84

5- Brasil. Ministério da Saúde. Coordenação Nacional de Saúde Bucal. Projeto SB Brasil 2003: condições de saúde bucal da população brasileira 2002-2003 - resultados principais. Brasília, DF: Ministério da Saúde; 2004 [acesso em 2005 abr. 30]. Disponível em: http://www.cfo.org.br/ download/pdf/relatorio SB brasil 2003.pdf.

6- Cypriano S, Sousa MLR, Rihs LB, Wada RS. Oral health among preschool children in Brazil, 1999. Rev Saude Publica. 2003;37:24753

7- Ferreira J. O corpo signo. In: Minayo MCS, Alves PC, editores Saúde e doença: um olhar antropológico. Rio de Janeiro: Fiocruz; 1998. p. 101-112.

8- Freire MCM. Oral health and sense of coherence: a study of brazilian adolescents and their mothers [dissertation]. London (UL): University of London; 1999.

9- Gillcrist JA, Brumley DE, Blackford JU. Community socioeconomic status and children's dental health. J Am Dent Assoc. 2001;132:21622 .

10-Gonçalves ER, Peres MA, Marcenes W. Dental caries and socioeconomic conditions: a cross-sectional study among 18 yearsold male in Florianopolis, Santa Catarina State, Brazil. Cad Saude Publica. 2002;18:699-706.

11 - Källestal C, Wall S. Socio-economic effect on caries. Incidence data among Swedish 12-14-year-olds. Community Dent and Oral Epidemiol. 2002;30:108-14.

12- Heft MW, Gilbert GH, Shelton BJ, Duncan RP. Relationship of dental status, socio-demographic status, and oral symptoms to perceived need for dental care. Community Dent Oral Epidemiol. 2003;31:351-60

13 - Hoffmann RHS, Cypriano S, Sousa MLR, Wada RS. Dental caries experience in children at public and private schools from a city with fluoridated water. Cad Saude Publica. 2004;20:522-8.

14- Hosmer DW, Lemeshow S. Applied logistic regression. New York: John Wiley \& Sons; 1989.

15- Macgregor ID, Balding JW, Regis D. Motivation for dental hygiene in adolescents. Int J Paediatr Dent. 1997;7:235-41.

16- Macgregor ID, Balding JW, Regis D. Flossing behavior in english adolescents. J Clin Periodontol. 1998;25:291-6.

17- Marthaler TM. Changes in dental caries: 1953-2003. Caries Res. $2004 ; 38: 173-81$
18 - Nadanovsky P, Sheiham A. Relative contribution of dental services to the changes in caries levels of 12-year-old children in 18 industrialized countries in the 1970s and early 1980s. Community Dent Oral Epidemiol. 1995;23:331-9.

19- Nishi M, Stjernswärd J, Carlsson P, Bratthall D. Caries experience of some countries and areas expressed by the significant caries index. Community Dent Oral Epidemiol. 2002;30:296-301.

20 - Brasil. Ministério da Saúde. Levantamento epidemiológico em saúde bucal: Brasil, zona urbana, 1986. Brasília, DF; 1988.

21 - Reid BC, Hyman JJ, Macek MD. Race/ethnicity and untreated dental caries: the impact of material and behavioral factors. Community Dent Oral Epidemiol. 2004;32:329-36.

22- Robinson PG, Nadanovsky P, Sheiham A. Can questionnaires replace clinical surveys to assess dental treatment needs of adults? J Public Health Dent. 1998;58:250-3

23 - Silva TA, Paixão HH, Pordeus IA. Behavior factors related with oral hygiene in adolescents. Arq Odontol. 1997;33:5-14.

24- Sogi GM, Bhaskar DJ. Dental caries and oral hygiene status of school children in Davangere related to their socio-economic levels: an epidemiological study. J Indian Soc Pedod Prev Dent. 2002;20:152-

25- Tamietti MB, Castilho LS, Paixão HH. Oral health education for adolescents: inadequacy of a traditional methodology. Arq Odontol. 1998;34:33-45.

26- Thomson WM, Locker D, Poulton R. Incidence of dental anxiety in young adults in relation to dental treatment experience. Community Dent Oral Epidemiol. 2000;28:289-94.

27- Truin GJ, Koning KG, Kalsbeek H. Trends in dental caries in the Netherlands. Adv Dent Res. 1993;7:15-8.

28 - Van Nieuwenhuysen JP, Carvalho JC, D'Hoore W. Caries reduction in Belgian 12-year-old children related to socioeconomic status. Acta Odontol Scand. 2002;60:123-8.

29- Vered Y, Sgan-Cohen HD. Self-perceived and clinically diagnosed dental and periodontal health status among young adults and their implications for epidemiological surveys. BMC Oral Health. 2003;3:3.

30 - World Health Organization. Oral health surveys, basic methods. 4th ed. Geneva: The Organization; 1997. 